\title{
Genotypic and phenotypic analysis of familial male breast cancer shows under representation of the HER2 and basal subtypes in BRCA-associated carcinomas
}

Siddhartha Deb ${ }^{1,2,3^{*}}$, Nicholas Jene ${ }^{1}$, kConFab investigators ${ }^{4}$ and Stephen B Fox ${ }^{1,3,4}$

\begin{abstract}
Background: Male breast cancer (MBC) is an uncommon and relatively uncharacterised disease accounting for $<1 \%$ of all breast cancers. A significant proportion occurs in families with a history of breast cancer and in particular those carrying BRCA2 mutations. Here we describe clinicopathological features and genomic BRCA1 and BRCA2 mutation status in a large cohort of familial MBCs.
\end{abstract}

Methods: Cases ( $\mathrm{n}=60$ ) included 3 BRCA1 and 25 BRCA2 mutation carries, and 32 non-BRCA1/2 (BRCAX) carriers with strong family histories of breast cancer. The cohort was examined with respect to mutation status, clinicopathological parameters including TNM staging, grade, histological subtype and intrinsic phenotype.

Results: Compared to the general population, MBC incidence was higher in all subgroups. In contrast to female breast cancer (FBC) there was greater representation of BRCA2 tumours (41.7\% vs 8.3\%, $\mathrm{p}=0.0008)$ and underrepresentation of BRCA1 tumours (5.0\% vs $14.4 \%, p=0.0001)$. There was no correlation between mutation status and age of onset, disease specific survival (DSS) or other clincopathological factors. Comparison with sporadic MBC studies showed similar clinicopathological features. Prognostic variables affecting DSS included primary tumour size ( $p=0.003$, HR:4.26 95\%Cl 1.63-11.11), age ( $p=0.002, \mathrm{HR}: 4.09$ 95\%Cl 1.65-10.12), lymphovascular ( $p=0.019$, HR:3.25 95\%Cl 1.21-8.74) and perineural invasion ( $p=0.027, \mathrm{HR}: 2.82$ 95\%Cl 1.13-7.06). Unlike familial FBC, the histological subtypes seen in familial MBC were more similar to those seen in sporadic MBC with 46 (76.7\%) pure invasive ductal carcinoma of no special type (IDC-NST), 2 (3.3\%) invasive lobular carcinomas and 4 (6.7\%) invasive papillary carcinoma. A further 8 (13.3\%) IDC-NST had foci of micropapillary differentiation, with a strong trend for co-occurrence in BRCA2 carriers ( $p=0.058)$. Most tumours were of the luminal phenotype (89.7\%), with infrequent HER2 (8.6\%) and basal (1.7\%) phenotype tumours seen.

Conclusion: MBC in BRCA1/2 carriers and BRCAX families is different to females. Unlike FBC, a clear BRCA1 phenotype is not seen but a possible BRCA2 phenotype of micropapillary histological subtype is suggested. Comparison with sporadic MBCs shows this to be a high-risk population making further recruitment and investigation of this cohort of value in further understanding these uncommon tumours.

Keywords: Male breast cancer, BRCA1, BRCA2, BRCAX, Micropapillary, Familial

\footnotetext{
* Correspondence: Deb@petermac.org

'Department of Anatomical Pathology, Peter MacCallum Cancer Centre, East Melbourne 3002, Australia

2 Victorian Cancer Biobank, Victorian Cancer Council, Carlton 3053, Australia

Full list of author information is available at the end of the article
} 


\section{Background}

Male breast cancer (MBC) is an infrequent and poorly characterised disease. Limited data to date suggests it is epidemiologically and biologically different from female breast cancer $(\mathrm{FBC})$ but it is unknown whether current paradigms and treatment of female disease can be extrapolated to the pathobiology and management of $\mathrm{MBC}$ and vice versa. Although some recent large MBC studies have been undertaken, these are population-based and this current report is the largest to describe the genotype, tumour phenotype, complete clinicopathological parameters and survival in $\mathrm{MBC}$ from high-risk families.

Accounting for less than $1 \%$ of all male cancers, and $0.65 \%$ of all breast tumours [1-3], the incidence of $\mathrm{MBC}$ has increased steadily from approximately 0.86 to 1.06 per 100,000 males over a 26 year period $[4,5]$ There is controversy surrounding mortality with some suggestion that $\mathrm{MBC}$ disproportionately accounts for a higher number of deaths than breast cancer in women [4-7] while other studies suggest parity when comparing age and stage matched cases [8].

Inherited risk factors for $\mathrm{MBC}$ appears to be a more significant contributor than in women with estimates of $10 \%$ of all $\mathrm{MBC}$ cases arising with a family pedigree suggestive of a genetic predisposition [2,9-11]. Unlike women, $B R C A 2$ germline mutation in men confers a significantly higher lifetime risk of developing breast cancer than BRCA1 [2,9-11]. Other genes also implicated in the development of MBC including PTEN [12], P53 [13] and CHEK2 1100delC [14]. Kleinfelter's syndrome (XXY) [15], environmental and hormonal states that alter the ratio of androgens to estrogens are also thought to contribute to MBC [16]. Recent meta-analysis has also shown an association between previous breast disease, in particular gynaecomastia, and occurrence of MBC [17]. It is still unclear, however, whether this is a; precursor lesion, a risk factor for $\mathrm{MBC}$ or whether the aetiology and pathogenesis is the same for both conditions.

Despite extensive knowledge about female BRCA1, $B R C A 2$ and other inherited familial breast tumours at present, little is know of male tumours from high-risk families. Comparison of sporadic tumours in both sexes shows; a steady linear increase in incidence in men with age in contrast to the bimodal distribution seen in $\mathrm{FBC}[2,3,18]$, an older median age of diagnosis in men $[6,8,18]$, more advanced stage-related tumour characteristics (tumour size $>2 \mathrm{~cm}$, positive axillary nodes) $[2,18]$ but with more favourable histopathological characteristics (lower tumour grade) and biology (hormone receptor positive tumours) $[2,18]$. Most MBC studies have been performed with cohorts predominantly composed of "sporadic" population based patients whereas this study is focused on one of the largest groups of MBCs arising in high-risk families evaluating both clinicopathological and genetic associations.
Table 1 Mutation carrier status and male breast cancer with the kConFab cohort

\begin{tabular}{llll}
\hline & BRCA1 & BRCA2 & Non-BRCA1/2 \\
\hline All males in kConFab registry & 429 & 339 & 19137 \\
Breast Cancers & $5(1.2 \%)$ & $35(10.3 \%)$ & $78(0.4 \%)$ \\
Pathology Available & 3 & 25 & 32 \\
\hline
\end{tabular}

\section{Methods}

\section{Study group}

Males with breast cancer were obtained from the kConFab repository (http://www.kconfab.org). Criteria for admission to the kConFab study has been previously published [19] (Additional file 1: Table S1) and patients were attained from within Australia and New Zealand between 1998 and 2009. The cases used in the analysis

Table 2 Characterisation of BRCA1 and 2 mutations of males included within this study

\begin{tabular}{lll}
\hline Gene & Mutation & Effect \\
\hline BRCA1 & BRCA1 del exons 21_24 & LGR \\
& BRCA1 2798_2801 del GAAA (STOP 998) & P \\
& BRCA1 5382_5383 ins C (STOP 1829) & P
\end{tabular}

BRCA2 BRCA2 del exons 1_2 LGR

BRCA2 del exons 14_16 LGR

BRCA2 2988 del C (STOP 959) P

BRCA2 2988 del C (STOP 959) P

BRCA2 5873 C>A (S1882X) P

BRCA2 5950_5951 del CT (STOP 1909) P

BRCA2 5950_5951 del CT (STOP 1909) P

BRCA2 6024_6025 del TA (STOP 1943) P

BRCA2 6503_6504 del TT (STOP 2098) P

BRCA2 6714_6717 del ACAA (STOP 2166) P

BRCA2 6854_6855 del TA (STOP 2223) P

BRCA2 6971_6983 del ATGCCACACATTC (STOP 2275) P

BRCA2 698_702 del AGTCA (STOP 180) P

BRCA2 7708 C>T (R2494X) P

BRCA2 8168_8169 ins C (STOP 2661) P

BRCA2 9132 del C (STOP 2975). P

BRCA2 9161 C>A (S2978X) P

BRCA2 9610 C > T (R3128X) P

BRCA2 9610 C > T (R3128X) P

BRCA2 983_986 del ACAG (STOP 275) P

BRCA2 995 del C (STOP 276) P

BRCA2 del exons 1_27 P

BRCA2 IVS 7-1 G>A P P

P BRCA2 8525 del C (STOP 2776). P

BRCA2 8714 A $>G$ (del exon 19)

UV

Classification of Variants: $P=$ Pathogenic, LGR $=$ Large Genomic Rearrangement, UV = Unclassified Variant. 
Table 3 Clinicopathological features

\begin{tabular}{|c|c|c|c|c|c|}
\hline & All patients $(n=60)$ & BRCA1 $(n=3)$ & BRCA2 $(n=25)$ & $\operatorname{BRCAX}(n=32)$ & P-value \\
\hline \multicolumn{6}{|l|}{ AGE AT DIAGNOSIS } \\
\hline Median & $62.5(30.1-85.6)$ & $65.6(49.5-80.1)$ & $61(31.0-85.7)$ & $63.2(30.1-81.8)$ & \\
\hline$<60$ yoa & $26(43.3 \%)$ & $1(33.3 \%)$ & $11(44.0 \%)$ & $14(43.8 \%)$ & \\
\hline$>60$ yoa & $34(56.7 \%)$ & $2(66.6 \%)$ & $14(56.0 \%)$ & $18(56.3 \%)$ & NS \\
\hline DISEASE SPECIFIC MORTALITY & $35.0 \%$ & $33.3 \%$ & $40.0 \%$ & $31.3 \%$ & \\
\hline \multicolumn{6}{|l|}{ SIDE } \\
\hline Right & $36(60.0 \%)$ & $1(33.3 \%)$ & $17(68.0 \%)$ & $18(56.2 \%)$ & \\
\hline Left & $24(40.0 \%)$ & $2(66.7 \%)$ & $8(32.0 \%)$ & $14(43.8 \%)$ & NS \\
\hline Unifocal & $56(93.3 \%)$ & $3(100 \%)$ & $22(88.0 \%)$ & $31(96.9 \%)$ & \\
\hline Multifocal & $2(3.3 \%)$ & 0 & $2(8.0 \%)$ & 0 & \\
\hline Bilateral & $2(3.3 \%)$ & 0 & $1(4.0 \%)$ & $1(3.1 \%)$ & NS \\
\hline \multicolumn{6}{|l|}{ HISTOLOGICAL SUBTYPE } \\
\hline Invasive Ductal Carcinoma - No special type & $46(76.7 \%)$ & $2(66.7 \%)$ & $18(72 \%)$ & $28(87.5 \%)$ & \\
\hline IDC with Micropapillary component & $8(13.3 \%)$ & 0 & $6(24 \%)$ & $2(6.3 \%)$ & \\
\hline Invasive Papillary Carcinoma & $4(6.7 \%)$ & $1(33.3 \%)$ & $1(4 \%)$ & $2(6.3 \%)$ & \\
\hline Invasive Lobular Carcinoma & $2(3.3 \%)$ & 0 & 0 & $2(6.3 \%)$ & NS \\
\hline \multicolumn{6}{|l|}{ BRE GRADE } \\
\hline 1 & $2(3.3 \%)$ & 0 & $1(4 \%)$ & $1(3.1 \%)$ & \\
\hline 2 & $31(51.7 \%)$ & 0 & $12(48 \%)$ & $19(59.4 \%)$ & \\
\hline 3 & $27(45.0 \%)$ & $3(100 \%)$ & $12(48 \%)$ & $12(37.5 \%)$ & NS \\
\hline \multicolumn{6}{|l|}{ ER STATUS (ALLRED 0-8) } \\
\hline 0 & $1(1.7 \%)$ & 0 & 0 & $1(3.3 \%)$ & \\
\hline $1-5$. & $5(8.6 \%)$ & $1(33.3 \%)$ & $2(8.0 \%)$ & $2(6.7 \%)$ & \\
\hline 6-8. & $52(89.7 \%)$ & $2(66.7 \%)$ & $23(92.0 \%)$ & $27(90.0 \%)$ & \\
\hline NA & 2 & 0 & 0 & 2 & NS \\
\hline \multicolumn{6}{|l|}{ PR STATUS (ALLRED 0-8) } \\
\hline 0 & $5(8.8 \%)$ & 0 & $1(4 \%)$ & $4(13.8 \%)$ & \\
\hline $1-5$. & $8(14.0 \%)$ & 0 & $5(20 \%)$ & $3(10.3 \%)$ & \\
\hline $6-8$. & $44(77.2 \%)$ & $3(100 \%)$ & $19(76 \%)$ & $22(75.9 \%)$ & \\
\hline NA & 3 & 0 & 0 & 3 & NS \\
\hline \multicolumn{6}{|l|}{ HER2 } \\
\hline Amplification & $5(9.1 \%)$ & 0 & $2(8.3 \%)$ & $3(10.7 \%)$ & \\
\hline Non-amplified & 50 (90.9\%) & $3(100 \%)$ & $22(91.7 \%)$ & $25(89.3 \%)$ & \\
\hline NA & 5 & 0 & 1 & 4 & NS \\
\hline \multicolumn{6}{|l|}{ PHENOTYPE } \\
\hline Basal & $1(1.7 \%)$ & 0 & 0 & $1(3.3 \%)$ & \\
\hline Luminal & $52(89.7 \%)$ & $3(100 \%)$ & $23(92.0 \%)$ & $26(86.7 \%)$ & \\
\hline HER2 & $5(8.6 \%)$ & 0 & $2(8.0 \%)$ & $3(10.0 \%)$ & \\
\hline NA & 2 & 0 & 0 & 2 & NS \\
\hline \multicolumn{6}{|l|}{ TUMOUR SIZE } \\
\hline Median & $17 \mathrm{~mm}(2-50 \mathrm{~mm})$ & $15 \mathrm{~mm}(9-25 \mathrm{~mm})$ & $17 \mathrm{~mm}(6-40 \mathrm{~mm})$ & $16(2-50 \mathrm{~mm})$ & \\
\hline \multicolumn{6}{|l|}{ TUMOUR STAGE } \\
\hline T1a & $1(1.7 \%)$ & 0 & 0 & $1(3.1 \%)$ & \\
\hline T1b & $8(13.3 \%)$ & 1 (33.3\%) & 4 (16.0\%) & 3 (9.4\%) & \\
\hline T1c & 31 (51.7\%) & 1 (33.3\%) & $10(40.0 \%)$ & 19 (59.4\%) & \\
\hline
\end{tabular}


Table 3 Clinicopathological features (Continued)

\begin{tabular}{|c|c|c|c|c|c|}
\hline $\mathrm{T} 2$ & $19(31.7 \%)$ & $1(33.3 \%)$ & $11(44.0 \%)$ & 7 (21.9\%) & \\
\hline T3 & $1(1.7 \%)$ & 0 & 0 & 1 & NS \\
\hline \multicolumn{6}{|l|}{ LYMPHOVASCULAR INVASION } \\
\hline Absent & $32(57.1 \%)$ & $2(66.7 \%)$ & $14(60.9 \%)$ & $16(53.3 \%)$ & \\
\hline Present & $24(42.9 \%)$ & $1(33.3 \%)$ & 9 (39.1\%) & $14(46.7 \%)$ & \\
\hline NA & 4 & 0 & 2 & 2 & NS \\
\hline \multicolumn{6}{|l|}{ PERINEURAL INVASION } \\
\hline Absent & $31(56.4 \%)$ & $3(100 \%)$ & $12(50.0 \%)$ & $16(57.1 \%)$ & \\
\hline Present & $24(43.6 \%)$ & 0 & $12(50.0 \%)$ & $12(42.9 \%)$ & \\
\hline NA & 5 & 0 & 1 & 4 & NS \\
\hline \multicolumn{6}{|l|}{ PAGET'S DISEASE OF NIPPLE } \\
\hline Absent & $44(84.6 \%)$ & $2(100 \%)$ & 19 (86.4\%) & $23(82.1 \%)$ & \\
\hline Present & $8(15.4 \%)$ & 0 & $3(13.6 \%)$ & $5(17.9 \%)$ & \\
\hline NA & 8 & 1 & 3 & 4 & NS \\
\hline \multicolumn{6}{|l|}{ NODAL STATUS } \\
\hline Cases with nodes examined & $46(76.7 \%)$ & $3(100 \%)$ & $20(80.0 \%)$ & $23(71.9 \%)$ & \\
\hline Cases with positive nodes & $20(43.4 \%)$ & $2(66.7 \%)$ & $9(45.0 \%)$ & $9(39.1 \%)$ & NS \\
\hline Average numbers of nodes examined per case & $12.9(1-30)$ & $16.3(13-24)$ & $15.9(1-30)$ & $10.1(1-29)$ & \\
\hline \multicolumn{6}{|l|}{ NODAL STAGE } \\
\hline No & $26(56.5 \%)$ & $1(33.3 \%)$ & $11(55.0 \%)$ & $14(60.1 \%)$ & \\
\hline N1 & $18(39.1 \%)$ & $2(66.7 \%)$ & $8(40.0 \%)$ & $8(34.8 \%)$ & \\
\hline N2 & $2(4.3 \%)$ & 0 & $1(5.0 \%)$ & $1(4.3 \%)$ & NS \\
\hline Cases with extranodal extension & $8(17.4 \%)$ & 0 & $5(25.0 \%)$ & $3(13.0 \%)$ & NS \\
\hline \multicolumn{6}{|l|}{ MARGINS } \\
\hline Clear & $29(48.3 \%)$ & $1(33.3 \%)$ & $12(48.0 \%)$ & $16(50.0 \%)$ & \\
\hline Involved & $15(25.0 \%)$ & 0 & $6(24.0 \%)$ & $9(28.1 \%)$ & \\
\hline Not assessable & $16(26.7 \%)$ & $2(66.7 \%)$ & 7 (28.0\%) & $7(21.9 \%)$ & NS \\
\hline \multicolumn{6}{|l|}{ DCIS } \\
\hline Absent & $14(25.0 \%)$ & 0 & 7 (29.2\%) & 7 (24.1\%) & \\
\hline NA & 4 & 0 & 1 & 3 & \\
\hline Present & $42(75.0 \%)$ & $3(100 \%)$ & 17 (70.8\%) & 22 (75.9\%) & NS \\
\hline \multicolumn{6}{|l|}{ Nuclear Grade } \\
\hline Low & $2(4.8 \%)$ & 0 & $2(11.8 \%)$ & 0 & \\
\hline Intermediate & 26 (61.9\%) & 1 (33.3\%) & $10(58.8 \%)$ & 15 (68.0\%) & \\
\hline High & 14 (33.3\%) & 2 (66.7\%) & 5 (29.4\%) & $7(31.8 \%)$ & NS \\
\hline
\end{tabular}

NS - Not significant.

had a diagnosis of breast cancer between 1980 - 2009. Clinical parameters, including TNM staging, tumour recurrence, occurrence of non-breast primary tumours and death were obtained from referring clinical centres, $\mathrm{kConFab}$ questionnaires and state death registries. Information on pedigree, mutational status and testing were available from the kConFab central registry. All available slides from all cases were reviewed by a pathologist for relevant histopathological parameters. Histological classification was based on criteria set by the World Health Organisation. This work was carried out with approval from the Peter MacCallum Cancer Centre Ethics Committee (Project No: 11/61).

\section{Mutation detection}

Mutation test results were generated through two avenues. If a clinic had performed mutation screening, the clinic report was passed onto the $\mathrm{kConFab}$ central registry. If no clinic mutation testing had been performed, the $\mathrm{kConFab}$ core research laboratory performed mutation testing. Testing for BRCA1 and BRCA2 mutations was performed on DNA extracted from $18 \mathrm{ml}$ sample of anticoagulated 
blood or mouthwash kit [20]. The blood processing protocol [21] generated a nucleated cell product for DNA extraction. DNA was extracted as required (QIAamp DNA blood kit, Qiagen GmbH, Hilden, Germany). Testing of index cases in kConFab families was carried out by denaturing high performance liquid chromatography or multiplex ligation-dependent probe amplification [22] $B R C A 1$ and BRCA2 variants were classified into the following categories with criteria as posted on kConFab's website [23]: pathogenic, splice-site variant, variant of unknown significance and polymorphism. Once the family mutation had been identified, all pathogenic (including splice site) variants of $B R C A 1$ and $B R C A 2$ were genotyped by kConFab in all available family members' DNA.

\section{Tissue microarrays (TMAs) and expression analysis by immunohistochemistry (IHC)}

TMAs were created from archival paraffin material. Two $1 \mathrm{~mm}$ cores were taken for each tumour. TMA sections were cut at $4 \mu \mathrm{m}$ thick intervals, de-waxed and hydrated. Antigen retrieval was performed according to manufacturers' instructions and endogenous peroxidase activity blocked before incubating sections with desired antibodies. Tumours were separated into molecular phenotypes as per Nielsen et al [24]. Expression of estrogen receptor- $\alpha$ (ER) (Ventana, clone SP1), progesterone receptor (PgR) (Ventana, clone 1E2), epidermal growth factor receptor (EGFR) (Zymed, clone 31G7) and cytokeratin (CK) 5 (Cell Marque, clone EP1601Y) was performed. HER2 amplification was assessed by silver in situ hybridisation (SISH) using the INFORM HER2 DNA probe (Ventana). Nuclear expression of ER and PgR was scored as per the Allred scoring system [25] (intensity + percentage of tumour cells staining, 0-8) and separated into absent (score 0/8), low (1-5/8) and high (6-8/8). HER2 gene status was reported as the average number of copies of the HER2 gene per cell in 30 tumour cells. Gene status was assessed as per the guidelines recommended by Wolff et al [26]. EGFR was scored positive for any membranous staining of tumour cells. Expression of CK5 was defined as positive when cytoplasmic and/or membranous staining was observed in tumour cells. Tumours were assigned to the following subtypes; Luminal (ER positive, HER2 negative), HER2 (HER2 positive), Basal (ER PgR and HER2 negative, CK5 and/or EGFR positive), and Null/negative (ER, PgR, HER2, CK5/6 and EGFR negative).

\section{Statistical analysis}

Comparison of groups was made with using MannWhitney $U$ for non-parametric continuous distributions and chi-square test for threshold data. Kaplan-Meier survival curves were plotted using breast cancer related death as the endpoint and compared using a log rank test. Regression analyses as time to fail curves were plotted for age of diagnosis and occurrence of second non breast primary tumours. Cox proportional hazard regression model was used to identify independent prognostic factors for disease specific survival (DSS). Analysis was performed with GraphPad Prism 5 software (GraphPad Prism version 5.04 for Windows, GraphPad Software, La Jolla California USA). A two-tailed P-value test was used in all analyses and a P-value or less than 0.05 was considered statistically significant.

\section{Results}

\section{Mutation analysis}

The prevalence of MBCs in the kConFab registry with known gene mutations is summarised in Table 1 and 2 . There were 5 (1.2\%) of 429 known $B R C A 1$ mutation carriers and $35(10.3 \%)$ of 339 BRCA2 carriers who developed breast cancer. Of these, 3 and 25 cases respectively had reports, slides and tissues available for examination and were included in the study. Of the 3 BRCA1 cases, 2 had a pathogenic mutation with 1 large genomic rearrangement. Of the $25 B R C A 2$ cases, 22 had a pathogenic mutation, 2 large genomic rearrangements and 1 an unclassified variant. Within non-BRCA1/2 families, of a total of 19,137 males, 78 (0.4\%) developed breast cancer with 32 cases available for use in the study.

\section{Clinicopathological features}

The clinicopathological features are summarised in Table 3. The overall median age of diagnosis was 62.5 years (range 30.1-85.6 years), and mean age of diagnosis 60.0 years. There was no significant difference in clinicopathological factors between $B R C A 1, B R C A 2$ carriers and BRCAX males including age of onset (Figure 1). Surgical treatment was by wide local excision (33.3\%, $20 / 60)$ and mastectomy $(66.6 \%, 40 / 60)$. All tumours

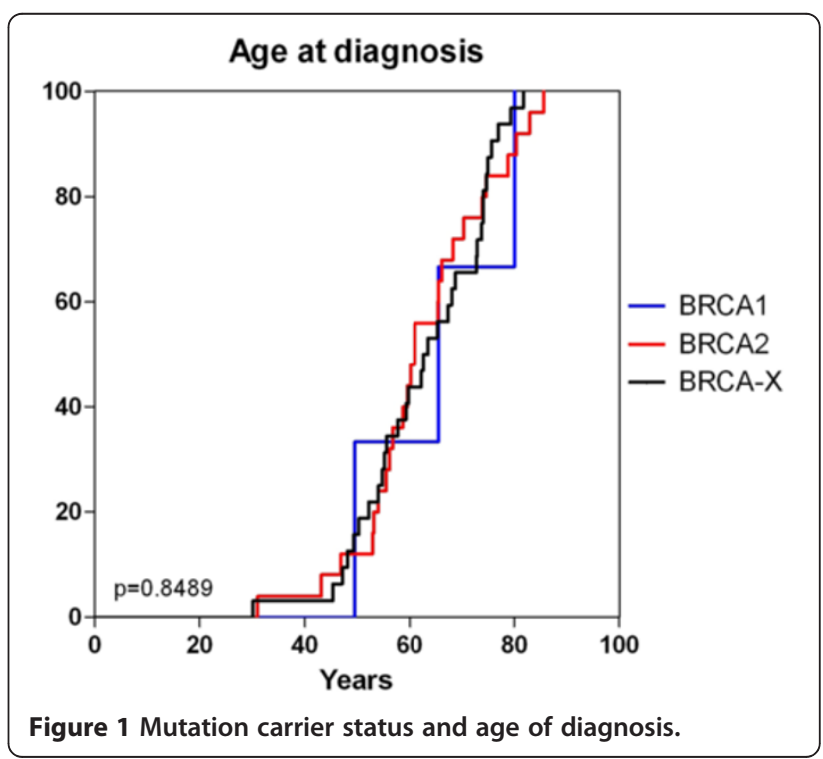



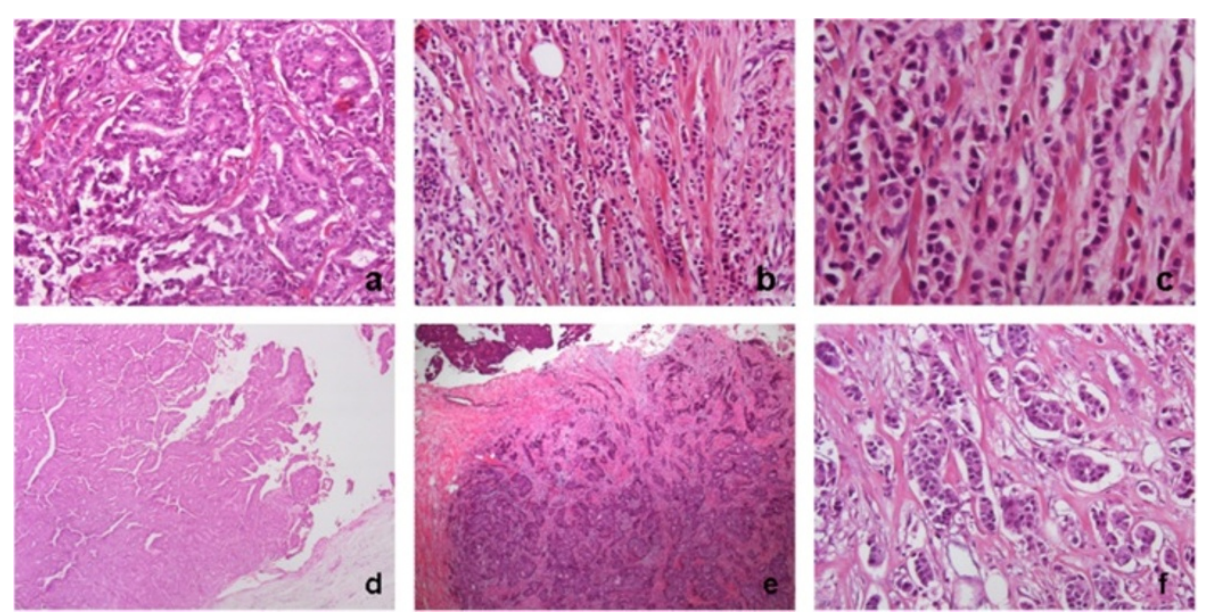

Figure 2 H\&E histological subtypes in male breast cancer: a) invasive ductal carcinoma of no special type, b) \& c) invasive lobular carcinoma, d) \& e) invasive papillary carcinoma, f) invasive micropapillary carcinoma.

were present within $30 \mathrm{~mm}$ of the subareolar region and the nipple. Four cases (6.6\%) had multifocal disease with 2 cases of bilateral breast cancer, of which one was a metachronous BRCAX tumour with a 10 year interval and the other a BRCA2 carrier with contralateral tumour occurring 12 years after the primary lesion.

Tumour size ranged from $2 \mathrm{~mm}$ to $50 \mathrm{~mm}$ (median $17 \mathrm{~mm}$ ). The most common histological subtype was infiltrating ductal carcinoma of no special type (IDC-NST) $(90 \%, 54 / 60)$ (Figure 2a) with 2 cases of invasive lobular carcinoma (3.3\%) (Figure $2 \mathrm{~b}$ and c) and 4 cases of invasive papillary carcinoma (6.7\%) (Figure $2 \mathrm{~d}$ and e). Of the
IDC-NST tumours, 8 had areas between 15 to $40 \%$ of invasive micropapillary carcinoma (Figure $2 \mathrm{f}$ ).

Tumours were of mainly grade $2(51.7 \%)$ and grade 3 (45.0\%). Lymphovascular and perineural invasion (PNI) was identified in $42.9 \%(24 / 56)$ and $43.6 \%(24 / 55)$ of cases respectively when able to be assessed. Paget's involvement of the nipple was seen in $15.4 \%$ of cases $(8 / 52)$ when assessable. Most tumours had a component of DCIS present $(75 \%, 42 / 56)$. Normal breast tissue and gynaecomastia was observed in $65.1 \%(28 / 43)$ and $11.6 \%(5 / 43)$ of cases respectively. Forty six cases had lymph node sampling with 7 sentinel node biopsy only (15.2\%) and
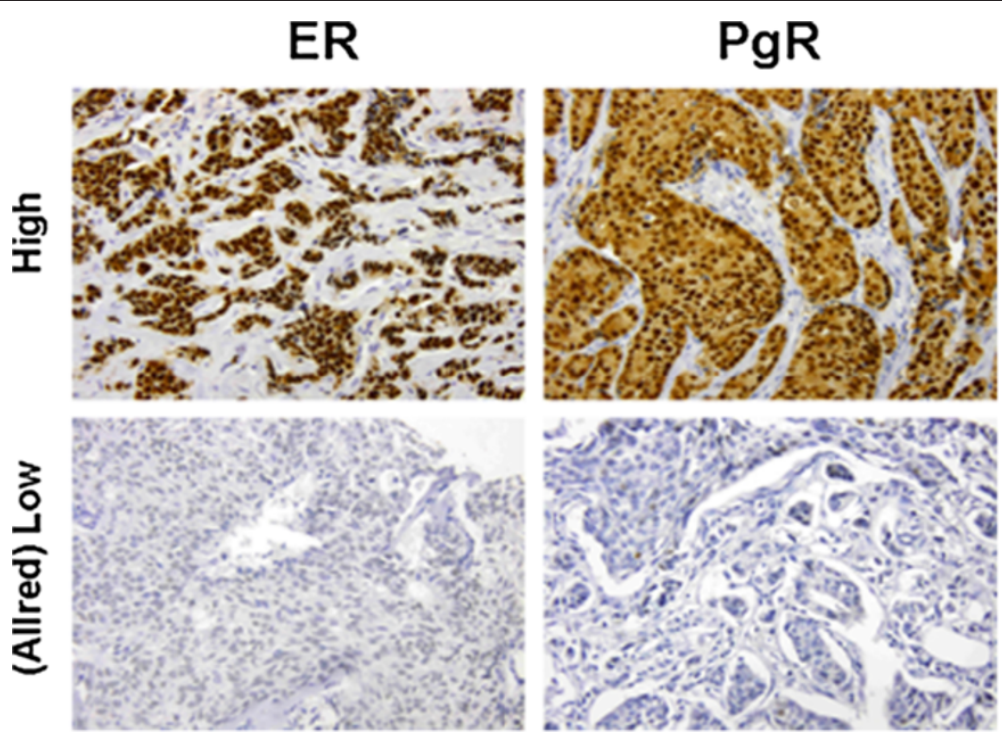

Figure 3 Immunohistochemical staining of male breast cancer for ER and PgR. 


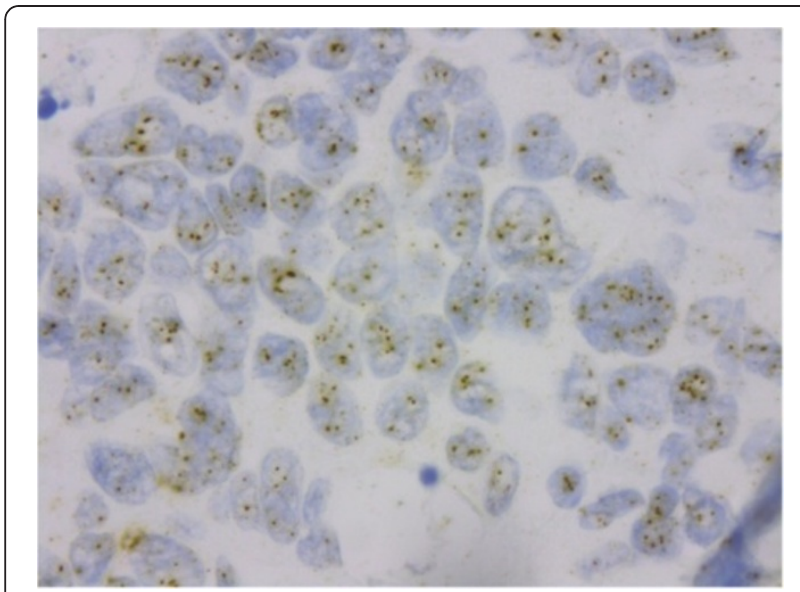

Figure 4 HER2 SISH demonstrating HER2 amplification in male breast cancer.

the remainder axillary dissection (84.7\%). On average 1.6 sentinel nodes (median 1, range 1-3) were examined and an average of 15 nodes from axillary dissections (median 13, range 4-30). Of these, 1 (14.3\%) sentinel node had metastatic disease and 19 axillary dissections had positive nodal disease (48.7\%) with extranodal extension in 8 cases.

Most tumours were ER and PgR positive (Additional file 2: Figures S1 and Additional file 3: Figure S2), with
89.7\% (52/58) and $77.2 \%(44 / 57)$ of cases respectively scored as high (Allred score 6-8/8) (Figure 3). HER2 amplification was seen in 9.1\% (5/55) of cases (Figure 4). The range of HER2 amplification was 6.1-10.5 signals per nuclei in amplified cases. Two tumours were unable to be immunophenotyped completely. Based on analysis of the remainder, the most common intrinsic subtype was Luminal $(89.7 \%, 52 / 58)$ followed by HER2 $(8.6 \%, 5 / 58)$ and Basal $(1.7 \%, 1 / 58)$. The Basal subtype (Figure 5$)$ was a BRCAX tumour with prominent CK5 and EGFR staining but also low ER nuclear positivity. Morphology of this tumour was more consistent with a basal subtype rather than a luminal type tumour.

There was a trend towards $B R C A 2$ tumours having an invasive micropapillary component $(24 \% 6 / 25, \mathrm{p}=0.0574)$ and high Bloom Richardson Ellis (BRE) grade for $B R C A 1$ tumours ( $100 \%$ grade $33 / 3, \mathrm{p}=0.0855$ ), however these observations did not reach statistical significance. Overall, clinicopathological factors and intrinsic subtypes were not associated with $B R C A 1$ or 2 mutation carrier status and unlike in female breast cancer [27], there was no association between BRCA1 mutational status and basal cell phenotype.

Characteristics are compared with other recent large $\mathrm{MBC}$ studies containing $>50$ patients and completed within the last 4 years [6-8,28-40] (Additional file 4: Table S2) and with the previous study of female breast cancers within the kConFab cohort [41].
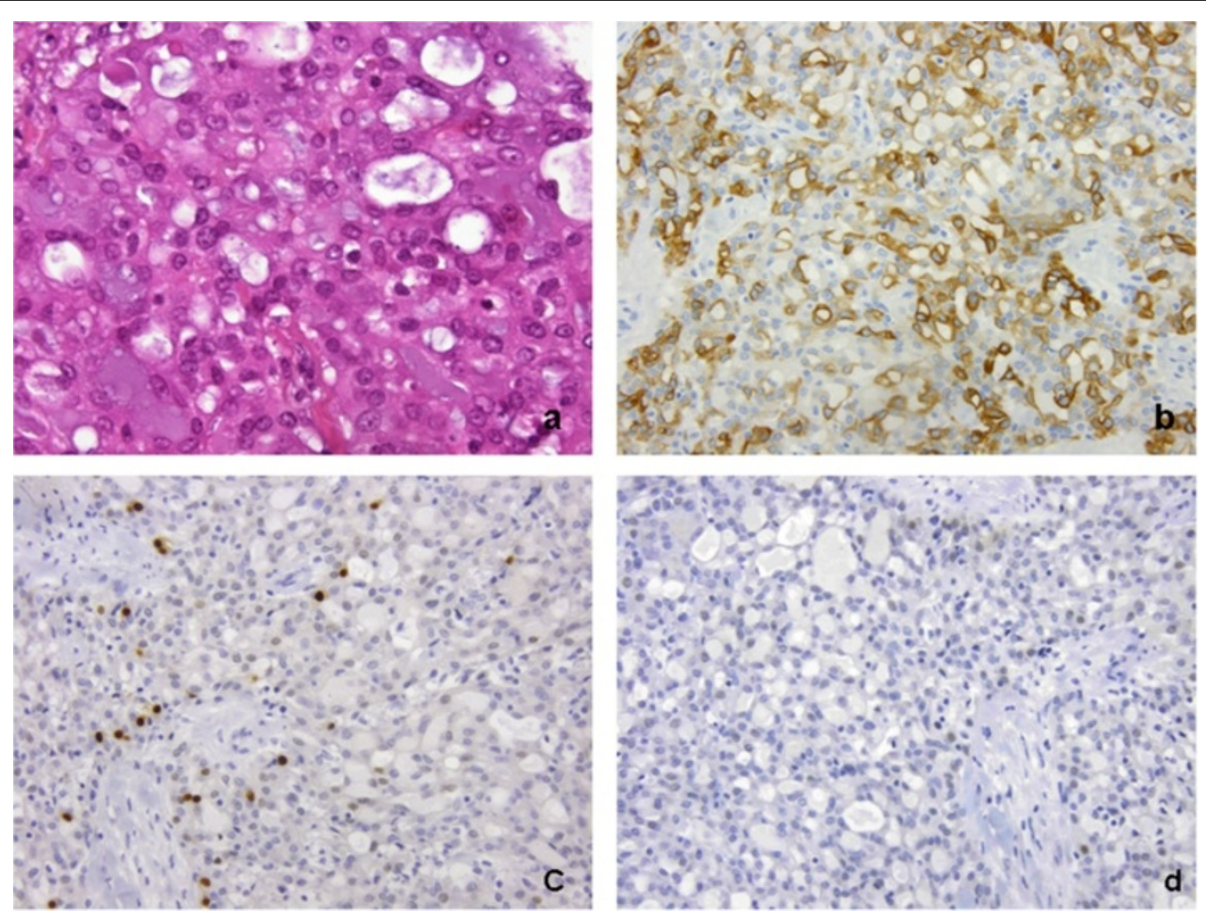

Figure 5 Male breast cancer of basal cell phenotype: a) H\&E, b) CK5, c) ER, d) PgR. 


\section{Disease specific survival}

The overall 5 and 10 year disease specific survival rates were $84.6 \%$ and $40.6 \%$ for all cases, $100 \%$ and $0 \%$ for BRCA1 case, $80.6 \%$ and $42.2 \%$ for BRCA2 cases and $86.7 \%$ and $41.2 \%$ for BRCAX cases (Figure 6). Clinicopathological variables (Figure 7) that were of prognostic significance for DSS included a primary tumour size $>2.0 \mathrm{~cm}$ (HR:4.26 95\%CI 1.63-11.11, $\mathrm{p}=0.003)$, age at diagnosis > 65 years (HR:4.09 95\%CI 1.65 -10.12, p=0.002), lymphovascular invasion (HR:3.25 95\%CI 1.21-8.74, $\mathrm{p}=0.019$ ) and PNI (HR:2.82 95\% CI 1.13-7.06, $\mathrm{p}=0.027$ ) (Table 4). A strong adverse trend for loss or low progesterone receptor expression was also seen (HR:2.59 95\%CI 0.86-7.80, $\mathrm{p}=0.091$ ) but fell short of being statistically significance.

Comparisons of mutation carrier status, tumour grade, presence of nodal disease, involvement of surgical margins and multifocality were not prognositically significant (all $\mathrm{p}>0.05)$.

\section{Second cancers}

Ten patients had a second major malignancy (5/25 BRCA2 mutation carriers, 5/31 BRCAX cases) (Table 5). No $B R C A 1$ patients developed a second malignancy. In eight $(80 \%)$ cases, the diagnosis of the primary breast tumour was the sentinel event while in two cases (20\%) another malignancy was diagnosed preceding the breast cancer. The median time to diagnosis was 3.8 years after the diagnosis of the breast cancer (range 3 years previous to 15.5 years after). The most common second malignancy was prostatic acinar adenocarinoma $(50 \%, 5 / 10)$. Of note, one patient had an adenocarcinoma of the abdominal wall of unknown primary origin with exclusion of a breast metastasis. Mutation carrier status was not prognostic of development of a second malignancy when comparing BRCA2 and BRCAX cohorts (Figure 8).

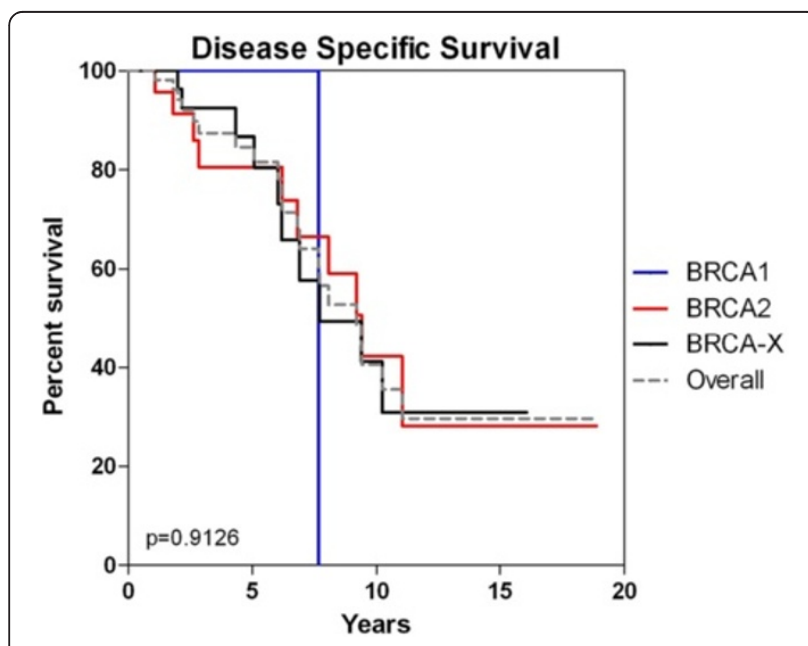

Figure 6 Mutation carrier status and disease specific survival.

\section{Discussion}

To the best of our knowledge this is the largest high-risk population based study to date describing the genotypic, conventional clinicopathological and intrinsic phenotypic characteristics of MBCs arising within breast cancer families. Previous studies have either not contained large numbers of patients with a significant family history $[30,34,35,37,43,47]$, not commented or examined family history $[6-8,28,29,36,39,40]$, or have contained large numbers of such cases with strong family pedigree but not described clinicopathological features [32] (Table 4). As a large proportion of MBCs are purported to arise in families with breast cancer and in particular BRCA2 mutation carriers, further description of this cohort is of significance in understanding and characterising the disease.

The incidence of MBC in BRCA2, BRCA1 and BRCAX males is significantly higher than the lifetime cumulative incidence of $0.1 \%$ in the general population $[17,48]$ confirming this group as a high risk for MBC. However, the representation of carriers is different to that of familial FBC with direct comparison within the kConFab registry [41] showing an increased proportion of $B R C A 2$ male carriers and underrepresentation of $B R C A 1$ male tumours. This suggests that significant gender associated modifiers such as high estrogen levels may affect $B R C A 1$ penetrance over BRCA2. Comparing studies of sporadic MBC [6-8, $28-32,35,37-40,44]$, the median and mean age of onset in our patients is also younger, and this together with the observation of frequent multifocality or bilateral disease reflects the pattern of cancer often seen with underlying genetic predisposition as seen in familial FBC. A recent large population based study by Ottini et al. [45] containing 46 BRCA2 mutation carriers also observed a high rate (15.2\%) of contralateral breast cancer in these carriers, thus supporting this observed pattern.

Compared with other MBC groups, our study appeared to have a higher proportion of high grade tumours with only $3.3 \%$ of tumours of BRE grade I, the lowest within any $\mathrm{MBC}$ cohort reported to date. We also reported the highest proportion of invasive papillary carcinomas with $6.7 \%$ of cases, the next highest in the literature being 5.5\% by Ottini et al. [45]. The histopathological tumour characteristics of our group otherwise is comparable to that seen in previous studies of sporadic MBC with the majority of cancers being invasive ductal carcinoma. This is higher than that seen in FBCs from kConFab [41]. Unlike FBC, we also observed proportionately less lobular carcinoma which is thought to reflect paucity of lobular and acinar units in males [49].

We also report a relatively higher proportion of tumours with invasive micropapillary areas particularly within BRCA2-associated tumours, an association not previously reported. Recent studies suggest that these 


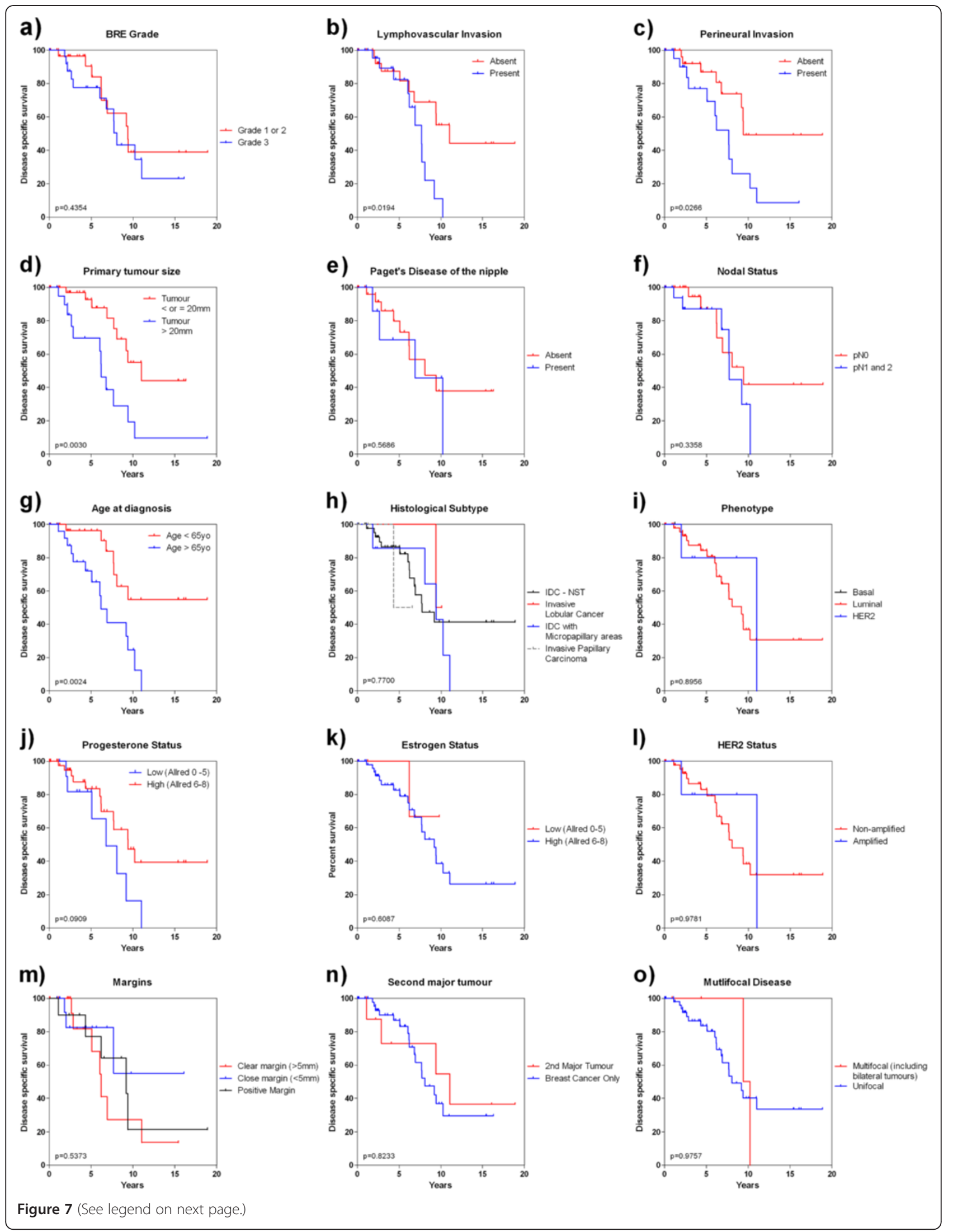


(See figure on previous page.)

Figure 7 Clinicopathological variables and disease specific survival: (a) BRE grade, (b) lymphovascular invasion, (c) perineural invasion, (d) primary tumour size, (e) Paget's disease of the nipple, (f) nodal status, (g) age at diagnosis, (h) histological subtype, (i) Intrinsic phenotype, (j) PgR immunohistochemical expression, (k) ER immunohistochemical expression, (l) HER2 amplification, (m) involvement of margins, (n) diagnosis of second non breast primary malignancy, (o) multifocal disease.

lesions are a distinct entity with more aggressive behaviour than IDC-NST [50]. The distinct histological features of these tumours correlate with distinct molecular genetic profiles [42], however, in female cancer a correlation with $B R C A 2$ mutation has not been described or suggested [10]. Ottini et al [45], also describe a BRCA2 MBC phenotype with a high proportion of BRE grade 3 tumours (54.8\%), loss of PgR expression (67.9\%) and HER2 amplification (63.2\%). Similar to them, our BRCA2 carriers contained a large proportion of BRE grade 3 but was not significantly different to the $B R C A 1$ and BRCAX population. The expression of ER and PgR in our familial MBCs is similar to that seen in sporadic $\mathrm{MBC}$, with proportionately higher levels than seen in $\mathrm{FBC}$, and absence of PgR expression did not discriminate a $B R C A 2$ phenotype. Subsequently, the majority of our cases were also of the luminal subtype. Reported HER2 amplification in MBC has been more variable than ER and PgR with studies demonstrating between $3.3 \%$ [40] to $28.4 \%$ [45] of cases showing HER2 amplification. While our study and Ottini are the only to date to examine the association with $B R C A$ status, using routine diagnostic testing for HER2 we see lower frequency of HER2 amplification both overall (9.1\%) and within our BRCA2 carriers (8.3\%) as a subgroup. Our results are consistent with most $\mathrm{MBC}$ studies that suggest HER2 amplification is seen half as frequently as that in $\mathrm{FBC}$ [41].

The few numbers of BRCA1 MBCs in our cohort precludes extensive clinicopathological analysis, however, in contrast and unlike tumours seen in BRCA1 female carriers $[27,51]$, cancers of medullary/basal cell phenotype in BRCA1 males has not been reported in the literature and was also not observed in our cohort of BRCA1 males. The paucity of tumours of basal phenotype in our

Table 4 Clinicopathological variables of prognostic significance

\begin{tabular}{llll}
\hline Variable & P-value & $\begin{array}{l}\text { Hazard's } \\
\text { ratio }\end{array}$ & $\begin{array}{l}\mathbf{9 5 \%} \text { confidence } \\
\text { interval }\end{array}$ \\
\hline Lymphovascular Invasion & 0.0194 & 3.25 & $1.21-8.74$ \\
Perineural Invasion & 0.0266 & 2.82 & $1.13-7.06$ \\
Tumour Size $>$ 20mm & 0.0030 & 4.26 & $1.63-11.11$ \\
Age of Diagnosis $>65$ years & 0.0024 & 4.09 & $1.65-10.12$ \\
Low Progesterone & 0.0909 & 2.59 & $0.86-7.80$ \\
Receptor Expression & & & \\
\hline
\end{tabular}

cohort overall also reflected observations of other $\mathrm{MBC}$ studies.

Several prognostic markers in our study are also reported in both $\mathrm{FBC}$ and sporadic MBC. In our study, we confirmed many but also identified PNI as being of prognostic significance, which has not been reported previously in $\mathrm{MBC}$. Its presence, being double most rates reported in $\mathrm{FBC}[52,53]$, may be due to frequent subareolar tumour location which is less frequently seen in women, and comparable to frequent perineural involvement seen in other epithelial tumours such as pancreatic [54] and prostatic [55] adenocarcinoma where the organs have closer proximity to nerve bundles. While mixed prognostic significance of PNI has been seen in FBC studies [53], PNI positive tumours have been shown to be more often associated with positive nodal status and hormonal positivity [53], both of which are more commonly seen in $\mathrm{MBC}$ in general, and in our study cohort when compared with FBC.

While our numbers are not large, a considerable proportion (16.6\%) of the BRCA2 and BRCAX patients developed a second non-breast primary malignancy. The onset or histological type of these tumours did not correlate with mutation carrier status. These findings are consistent with those previously reported in $\mathrm{MBC}$ cohorts where the range of second cancer incidence varies between $5.9 \%$ to $22.8 \%$ when reported $[8,28,30,31,34,35]$. Notably, the studies with higher rates of breast cancer families such as Ding [31] (60\% either BRCA2 pathogenic mutation carrier or strong family history of breast cancer), Liukkonen[35] (33.1\% with significant familial history) and Kiluk [34] (29\% with significant familial history) had $22.8 \%, 19 \%$ and $19.4 \%$ of their patients reporting a second primary respectively. Of the types reported, prostate cancer was the most common followed by bladder cancer, a tumour type not seen in our cohort. In recent studies we and others have demonstrated the relative risk for developing prostate cancer in male BRCA2 mutation carriers as between 2.9 to 4.8 times the general population [56-59]. Comparing our study with the age related rate of Australian males in the 60-64 year age group, there is an increased relative risk of prostate cancer of $19.08(\mathrm{p}<0.0001,95 \% \mathrm{CI} 4.50-80.91)$ and $20.56(\mathrm{p}<0.0001,95 \% \mathrm{CI}$ 6.30-67.12) times the normal population for BRCA2 and BRCAX male patients with breast cancer respectively. These data show that patients with $\mathrm{MBC}$ may be a high-risk group for developing second malignancies, even when comparing with BRCA2 carriers 
Table 5 Second non-breast primary malignancies

\begin{tabular}{llll}
\hline Gene & Mutation & 2nd tumour & Diagnosis relative to Breast Primary (years) \\
\hline BRCA2 & BRCA2 2988 del C (STOP 959) & Ascending Colon - Adenocarcinoma & 15.5 \\
BRCA2 & BRCA2 698_702 del AGTCA (STOP 180) & Prostate - Acinar Adenocarcinoma & 0.8 \\
BRCA2 & BRCA2 8168_8169 ins C (STOP 2661) & Prostate - Acinar Adenocarcinoma & 1.4 \\
BRCA2 & BRCA2 del exons 1_27 & Parotid gland - Oxyphilic adenocarcinoma & 6.2 \\
BRCA2 & BRCA2 IVS 7-1 G>A & Lung - squamous cell carcinoma & 13.8 \\
BRCAX & Adenocarcinoma - unknown primary & 3.0 \\
BRCAX & Lung - Carcinoma not otherwise specified. & 9.4 \\
BRCAX & Prostate - Acinar Adenocarcinoma & 9.5 \\
BRCAX & Prostate - Acinar Adenocarcinoma & 3.0 years prior to breast cancer \\
BRCAX & Prostate - Acinar Adenocarcinoma & 1.3 years prior to breast cancer \\
\hline
\end{tabular}

without MBC. Whether this is due to hormonal influence driving both tumour types or underlying genetic factors requires further study in a larger data set.

\section{Conclusions}

This is the largest clinicopathological study of male breast cancers arising in breast cancer families. It identifies three high-risk population groups (BRCA1/2, BRCAX) which may be important for screening for male breast cancer. The clinical and pathological characteristics are different to familial female breast cancer but similar to previously described male breast cancer studies which have contained but not separately analysed sporadic and familial breast cancers. Notably, our study in comparison contains proportionately more multifocal disease, a younger age of onset and a significant proportion with a second major malignancy, features often seen in tumours that arise with a genetic predisposition. BRCA2 mutation status did not appear to correlate with a distinct clinicopathological phenotype or disease behaviour, and a strong trend was seen within BRCA2 carrier tumours containing areas of

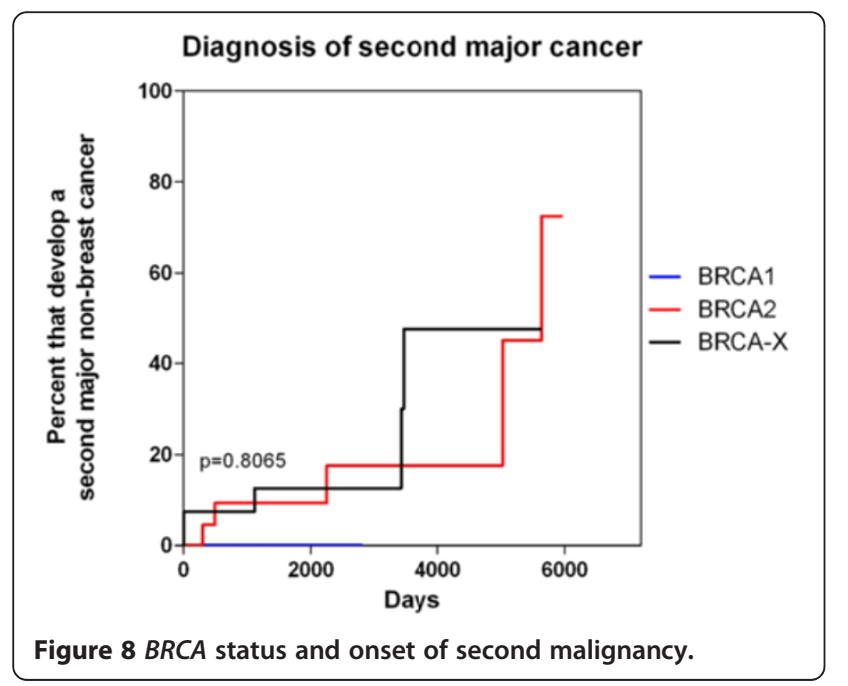

micropapillary carcinoma possible suggesting a possible $B R C A 2$ male breast cancer phenotype. Further subgroup analysis, in particular of BRCA1 tumours, was limited by the number of cases available. Further recruitment of well characterised tumours in breast cancer families, in particular a focused collection of BRCA1 cases, is warranted to validate and characterise familial $M B C$ further.

\section{Additional files}

Additional file 1: Table S1. Eligibility criteria for recruitment of families into kConFab.

Additional file 2: Figure S1. Distribution of ER Allred histoscores. Additional file 3: Figure S2. Distribution of PgR Allred histoscores. Additional file 4: Table 2. Comparison of previous MBC studies.

\section{Abbreviations}

MBC: Male Breast Cancer; FBC: Female Breast Cancer; DSS: Disease Specific Survival; ER: Estrogen Receptor; PgR: Progesterone Receptor; CK: Cytokeratin; EGFR: Epidermal Growth Factor Receptor; IDC-NST: Invasive Ductal Carcinoma of No Special Type; PNI: Perineural Invasion; BRE: Bloom Richardson Ellis.

\section{Competing interests}

The authors declare they have no competing interests.

\section{Authors' contributions}

SD - Pathology review of all cases, conception and design of study, analysis and interpretation of data, statistical analysis, manuscript preparation, NJ Immunohistochemistry and ISH, kConFab Investigators - BRCA1/2 testing, acquisition of all data, manuscript preparation, SBF - Conception and design of study, analysis and interpretation of data, manuscript preparation. All authors read and approved the final manuscipt.

\section{Acknowledgements}

SD, NJ and SBF received support from the Peter MacCallum Cancer Centre, the National Health and Medical Research Council (NHMRC) and the Victorian Biobank. We wish to thank Heather Thorne, Eveline Niedermayr, all the kConFab research nurses and staff, the heads and staff of the Family Cancer Clinics, and the Clinical Follow Up Study (funded 2001-2009 by NHMRC and currently by the National Breast Cancer Foundation and Cancer Australia \#628333) for their contributions to this resource, and the many families who contribute to kConFab. KConFab is supported by grants from the National Breast Cancer Foundation, the NHMRC and by the Queensland Cancer Fund, the Cancer Councils of New South Wales, Victoria, Tasmania and South Australia, and the Cancer Foundation of Western Australia. 


\section{Author details}

${ }^{1}$ Department of Anatomical Pathology, Peter MacCallum Cancer Centre, East Melbourne 3002, Australia. ${ }^{2}$ Victorian Cancer Biobank, Victorian Cancer Council, Carlton 3053, Australia. ${ }^{3}$ Department of Pathology, University of Melbourne, Parkville 3052, Australia. ${ }^{4}$ Kathleen Cuningham Foundation Consortium for research into Familial Breast Cancer, Peter MacCallum Cancer Centre, East Melbourne 3002, Australia.

Received: 28 May 2012 Accepted: 5 October 2012

Published: 9 November 2012

\section{References}

1. Weiss JR, Moysich KB, Swede H: Epidemiology of male breast cancer. Cancer epidemiology, biomarkers \& prevention: a publication of the American Association for Cancer Research, cosponsored by the American Society of Preventive Oncology 2005, 14(1):20-26.

2. Korde LA, Zujewski JA, Kamin L, Giordano S, Domchek S, Anderson WF, Bartlett JM, Gelmon K, Nahleh Z, Bergh J, et al: Multidisciplinary meeting on male breast cancer: summary and research recommendations. J Clin Oncol 2010, 28(12):2114-2122.

3. SEER Database. http://seer.cancer.gov/.

4. Jemal A, Siegel R, Ward E, Hao Y, Xu J, Thun MJ: Cancer statistics, 2009. CA: a cancer journal for clinicians 2009, 59(4):225-249.

5. Jemal A, Tiwari RC, Murray T, Ghafoor A, Samuels A, Ward E, Feuer EJ, Thun MJ: Cancer statistics, 2004. CA: a cancer journal for clinicians 2004, 54(1):8-29.

6. Nilsson C, Holmqvist M, Bergkvist L, Hedenfalk I, Lambe M, Fjallskog ML: Similarities and differences in the characteristics and primary treatment of breast cancer in men and women - a population based study (Sweden). Acta oncologica (Stockholm, Sweden) 2011, 50(7):1083-1088.

7. Anderson WF, Jatoi I, Tse J, Rosenberg PS: Male breast cancer: a population-based comparison with female breast cancer. J Clin Oncol 2010, 28(2):232-239.

8. Foerster R, Foerster FG, Wulff $V$, Schubotz B, Baaske D, Wolfgarten M, Kuhn WC, Rudlowski C: Matched-pair analysis of patients with female and male breast cancer: a comparative analysis. BMC cancer 2011, 11:335.

9. Basham VM, Lipscombe JM, Ward JM, Gayther SA, Ponder BA, Easton DF, Pharoah PD: BRCA1 and BRCA2 mutations in a population-based study of male breast cancer. Breast cancer research: $B C R$ 2002, 4(1):R2.

10. Evans DG, Bulman M, Young $K$, Gokhale D, Lalloo F: High detection rate for BRCA2 mutations in male breast cancer families from North West England. Familial cancer 2001, 1(3-4):131-133.

11. Thompson D, Easton D: Variation in cancer risks, by mutation position, in BRCA2 mutation carriers. Am J Hum Genet 2001, 68(2):410-419.

12. Fackenthal JD, Marsh DJ, Richardson AL, Cummings SA, Eng C, Robinson BG, Olopade OI: Male breast cancer in Cowden syndrome patients with germline PTEN mutations. J Med Gen 2001, 38(3):159-164.

13. Anelli A, Anelli TF, Youngson B, Rosen PP, Borgen PI: Mutations of the $\mathrm{p} 53$ gene in male breast cancer. Cancer 1995, 75(9):2233-2238.

14. Wasielewski M, den Bakker MA, van den Ouweland A, Meijer-van Gelder ME, Portengen H, Klijn JG, Meijers-Heijboer H, Foekens JA, Schutte M: CHEK2 $1100 \mathrm{delC}$ and male breast cancer in the Netherlands. Breast Cancer Res Treat 2009, 116(2):397-400.

15. Evans DB, Crichlow RW: Carcinoma of the male breast and Klinefelter's syndrome: is there an association? CA: a cancer journal for clinicians 1987, 37(4):246-251.

16. Brinton LA, Richesson DA, Gierach GL, Lacey JV Jr, Park Y, Hollenbeck AR, Schatzkin A: Prospective evaluation of risk factors for male breast cancer. J Nat Cancer Inst 2008, 100(20):1477-1481.

17. Sasco AJ, Lowenfels AB, Pasker-de Jong P: Review article: epidemiology of male breast cancer. A meta-analysis of published case-control studies and discussion of selected aetiological factors. Int J Cancer J Int du, cancer 1993, 53(4):538-549.

18. Anderson WF, Althuis MD, Brinton LA, Devesa SS: Is male breast cancer similar or different than female breast cancer? Breast Cancer Res Treat 2004, 83(1):77-86.

19. Mann GJ, Thorne H, Balleine RL, Butow PN, Clarke CL, Edkins E, Evans GM, Fereday S, Haan E, Gattas M, et al: Analysis of cancer risk and BRCA1 and BRCA2 mutation prevalence in the kConFab familial breast cancer resource. Breast Cancer Res: BCR 2006, 8(1):R12.

20. Lum A, Le Marchand L: A simple mouthwash method for obtaining genomic DNA in molecular epidemiological studies. Cancer epidemiology, biomarkers \& prevention: a publication of the American Association for Cancer Research, cosponsored by the American Society of Preventive Oncology 1998, 7(8):719-724.

21. kConFab Biospecimen Protocol. http://www.kconfab.org/epidemiology/ biospecimen_protocol.html.

22. Hogervorst FB, Nederlof PM, Gille JJ, McElgunn CJ, Grippeling M, Pruntel R, Regnerus R, van Welsem T, van Spaendonk R, Menko FH, et al: Large genomic deletions and duplications in the BRCA1 gene identified by a novel quantitative method. Cancer Res 2003, 63(7):1449-1453.

23. kConFab Classification of BRCA1 and BRCA2 Mutations. http://www.kconfab. org/progress/mutations.asp

24. Nielsen TO, Hsu FD, Jensen K, Cheang M, Karaca G, Hu Z, HernandezBoussard T, Livasy C, Cowan D, Dressler L, et al: Immunohistochemical and clinical characterization of the basal-like subtype of invasive breast carcinoma. Clinical Cancer Res: an official journal of the American Association for Cancer Research 2004, 10(16):5367-5374.

25. Leake R, Barnes D, Pinder S, Ellis I, Anderson L, Anderson T, Adamson R, Rhodes T, Miller K, Walker R: Immunohistochemical detection of steroid receptors in breast cancer: a working protocol. UK Receptor Group, UK NEQAS, The Scottish Breast Cancer Pathology Group, and The Receptor and Biomarker Study Group of the EORTC. J Clin Pathol 2000, 53(8):634635

26. Wolff AC, Hammond ME, Schwartz JN, Hagerty KL, Allred DC, Cote RJ, Dowsett M, Fitzgibbons PL, Hanna WM, Langer A, et al: American Society of Clinical Oncology/College of American Pathologists guideline recommendations for human epidermal growth factor receptor 2 testing in breast cancer. J Clin Oncol 2007, 25(1):118-145.

27. Lakhani SR, Reis-Filho JS, Fulford L, Penault-Llorca F, van der Vijver M, Parry S, Bishop T, Benitez J, Rivas C, Bignon YJ, et al: Prediction of BRCA1 status in patients with breast cancer using estrogen receptor and basal phenotype. Clinical Cancer Res: an official journal of the American Association for Cancer Research 2005, 11(14):5175-5180.

28. Arslan UY, Oksuzoglu B, Ozdemir N, Aksoy S, Alkis N, Gok A, Kaplan MA, Gumus M, Berk V, Uncu D, et al: Outcome of non-metastatic male breast cancer: 118 patients. Med Oncol (Northwood, London, England) 2011, 29(2):554-60.

29. Bourhafour M, Belbaraka R, Souadka A, M'Rabti H, Tijami F, Errihani H: Male breast cancer: a report of 127 cases at a Moroccan institution. BMC Res notes 2011, 4:219.

30. Cutuli B, Le-Nir CC, Serin D, Kirova Y, Gaci Z, Lemanski C, De Lafontan B, Zoubir M, Maingon P, Mignotte $H$, et al: Male breast cancer. Evolution of treatment and prognostic factors. Analysis of 489 cases. Critical reviews in oncology/hematology 2010, 73(3):246-254.

31. Ding YC, Steele L, Kuan CJ, Greilac S, Neuhausen SL: Mutations in BRCA2 and PALB2 in male breast cancer cases from the United States. Breast Cancer Res Treatment 2011, 126(3):771-778.

32. Evans DG, Bulman M, Young K, Howard E, Bayliss S, Wallace A, Lalloo F: BRCA1/2 mutation analysis in male breast cancer families from North West England. Familial cancer 2008, 7(2):113-117.

33. Johansson I, Nilsson C, Berglund P, Strand C, Jonsson G, Staaf J, Ringner M Nevanlinna H, Barkardottir RB, Borg A, et al: High-resolution genomic profiling of male breast cancer reveals differences hidden behind the similarities with female breast cancer. Breast cancer research and treatment 2011, 129(3):747-760.

34. Kiluk JV, Lee MC, Park CK, Meade T, Minton S, Harris E, Kim J, Laronga C: Male breast cancer: management and follow-up recommendations. The Breast J 2011, 17(5):503-509.

35. Liukkonen S, Saarto T, Maenpaa H, Sjostrom-Mattson J: Male breast cancer: a survey at the Helsinki University Central Hospital during 1981-2006. Acta Oncol(Stockholm, Sweden) 2010, 49(3):322-327.

36. Miao H, Verkooijen HM, Chia KS, Bouchardy C, Pukkala E, Laronningen S, Mellemkjaer L, Czene K, Hartman M: Incidence and outcome of male breast cancer: an international population-based study. J Clin Oncol 2011, 29(33):4381-4386.

37. Nahleh ZA, Srikantiah R, Safa M, Jazieh AR, Muhleman A, Komrokji R: Male breast cancer in the veterans affairs population: a comparative analysis. Cancer 2007, 109(8):1471-1477.

38. Ottini L, Rizzolo P, Zanna I, Falchetti M, Masala G, Ceccarelli K, Vezzosi V, Gulino A, Giannini G, Bianchi S, et al: BRCA1/BRCA2 mutation status and clinical-pathologic features of 108 male breast cancer cases from Tuscany: a population-based study in central Italy. Breast Cancer Res Treat 2009, 116(3):577-586. 
39. Shaaban AM, Ball GR, Brannan RA, Cserni G, Benedetto AD, Dent J, Fulford L, Honarpisheh $H$, Jordan $L$, Jones $J$, et al: A comparative biomarker study of 514 matched cases of male and female breast cancer reveals gender-specific biological differences. Breast Cancer Res Treat 2011, 33(3):949-58.

40. Zhou FF, Xia LP, Wang X, Guo GF, Rong YM, Qiu HJ, Zhang B: Analysis of prognostic factors in male breast cancer: a report of 72 cases from a single institution. Chinese J Cancer 2010, 29(2):184-188.

41. Loughrey M, Provan PJ, Byth K, Balleine RL: Histopathological features of 'BRCAX' familial breast cancers in the kConFab resource. Pathology 2008, 40(4):352-358.

42. Marchio C, Iravani M, Natrajan R, Lambros MB, Savage K, Tamber N, Fenwick K, Mackay A, Senetta R, Di Palma S, et al: Genomic and immunophenotypical characterization of pure micropapillary carcinomas of the breast. J Pathol 2008, 215(4):398-410.

43. Johansen Taber KA, Morisy LR, Osbahr AJ 3rd, Dickinson BD: Male breast cancer: risk factors, diagnosis, and management (Review). Oncol reports 2010, 24(5):1115-1120.

44. Marchal F, Salou M, Marchal C, Lesur A, Desandes E: Men with breast cancer have same disease-specific and event-free survival as women. Annals Surg Oncol 2009, 16(4):972-978.

45. Ottini L, Silvestri V, Rizzolo P, Falchetti M, Zanna I, Saieva C, Masala G, Bianchi S, Manoukian S, Barile M, et al: Clinical and pathologic characteristics of BRCA-positive and BRCA-negative male breast cancer patients: results from a collaborative multicenter study in Italy. Breast Cancer Res Treat 2012, 134(1):411-418.

46. Tavassoli FA, Devilee P, Organization WH, Cancer IAR: Pathology and genetics of tumours of the breast and female genital organs. Lyon, France: IARC Press; 2003.

47. Ottini L, Masala G, D'Amico C, Mancini B, Saieva C, Aceto G, Gestri D, Vezzosi $\checkmark$, Falchetti M, De Marco M, et al: BRCA1 and BRCA2 mutation status and tumor characteristics in male breast cancer: a population-based study in Italy. Cancer Res 2003, 63(2):342-347.

48. Fentiman IS, Fourquet A, Hortobagyi GN: Male breast cancer. Lancet 2006, 367(9510):595-604.

49. Ouriel K, Lotze MT, Hinshaw JR: Prognostic factors of carcinoma of the male breast. Surg gynecol Obstet 1984, 159(4):373-376.

50. Nassar H: Carcinomas with micropapillary morphology: clinical significance and current concepts. Adv Anatomic Pathol 2004, 11(6):297-303.

51. Lakhani SR, Jacquemier J, Sloane JP, Gusterson BA, Anderson TJ, van de Vijver MJ, Farid LM, Venter D, Antoniou A, Storfer-Isser A, et al: Multifactorial analysis of differences between sporadic breast cancers and cancers involving BRCA1 and BRCA2 mutations. J Nat Cancer Inst 1998 90(15):1138-1145.

52. Cetintas SK, Kurt M, Ozkan L, Engin K, Gokgoz S, Tasdelen I: Factors influencing axillary node metastasis in breast cancer. Tumori 2006 92(5):416-422.

53. Duraker N, Caynak ZC, Turkoz K: Perineural invasion has no prognostic value in patients with invasive breast carcinoma. Breast (Edinburgh, Scotland) 2006, 15(5):629-634.

54. Ozaki H, Hiraoka T, Mizumoto R, Matsuno S, Matsumoto $Y$, Nakayama T, Tsunoda T, Suzuki T, Monden M, Saitoh $Y$, et al: The prognostic significance of lymph node metastasis and intrapancreatic perineural invasion in pancreatic cancer after curative resection. Surg Today 1999, 29(1):16-22

55. Masieri L, Lanciotti M, Nesi G, Lanzi F, Tosi N, Minervini A, Lapini A, Carini M, Serni S: Prognostic role of perineural invasion in 239 consecutive patients with pathologically organ-confined prostate cancer. Urologia internationalis 2010, 85(4):396-400.

56. Cancer risks in BRCA2 mutation carriers. The Breast Cancer Linkage Consortium. J Nat Cancer Inst 1999, 91(15):1310-1316.

57. Easton DF, Steele L, Fields P, Ormiston W, Averill D, Daly PA, McManus R, Neuhausen SL, Ford D, Wooster $\mathrm{R}$, et al: Cancer risks in two large breast cancer families linked to BRCA2 on chromosome 13q12-13. Am J Human Genet 1997, 61(1):120-128.

58. Kirchhoff $T$, Kauff ND, Mitra N, Nafa K, Huang H, Palmer C, Gulati T, Wadsworth E, Donat S, Robson ME, et al: BRCA mutations and risk of prostate cancer in Ashkenazi Jews. Clinical Cancer Res: an official journal of the American Association for Cancer Research 2004, 10(9):2918-2921.
59. Willems AJ, Dawson SJ, Samaratunga H, De Luca A, Antill YC, Hopper JL, Thorne HJ: Loss of heterozygosity at the BRCA2 locus detected by multiplex ligation-dependent probe amplification is common in prostate cancers from men with a germline BRCA2 mutation. Clinical Cancer Res: an official journal of the American Association for Cancer Research 2008, 14(10):2953-2961.

doi:10.1186/1471-2407-12-510

Cite this article as: Deb et al:: Genotypic and phenotypic analysis of familial male breast cancer shows under representation of the HER2 and basal subtypes in BRCA-associated carcinomas. BMC Cancer 2012 12:510.

\section{Submit your next manuscript to BioMed Central and take full advantage of:}

- Convenient online submission

- Thorough peer review

- No space constraints or color figure charges

- Immediate publication on acceptance

- Inclusion in PubMed, CAS, Scopus and Google Scholar

- Research which is freely available for redistribution 